\title{
Correlation Between Quality and Geographical Origins of Leonuri Herba Revealed By the Qualitative Fingerprint Profiling and Quantitative Determination of Chemical Components
}

\author{
Kelly Yinching Lam \\ Hong Kong Baptist University School of Chinese Medicine \\ Yinghao Wang \\ Hong Kong Baptist University School of Chinese Medicine \\ Tszking Lam \\ Hong Kong Baptist University School of Chinese Medicine \\ Chuenfai Ku \\ Hong Kong Baptist University School of Chinese Medicine \\ Wingping Yeung \\ Hong Kong Baptist University School of Chinese Medicine \\ Zhongzhen Zhao ( $\square$ zzzhao@hkbu.edu.hk) \\ Hong Kong Baptist University https://orcid.org/0000-0002-6533-9668
}

\section{Research Article}

Keywords: Geographical Origins, Leonuri Herba, fingerprint, Chemical components

Posted Date: December 7th, 2021

DOI: https://doi.org/10.21203/rs.3.rs-1102170/v1

License: (c) (1) This work is licensed under a Creative Commons Attribution 4.0 International License. Read Full License

Version of Record: A version of this preprint was published at Chinese Medicine on April 12th, 2022. See the published version at https://doi.org/10.1186/s13020-022-00592-w. 


\section{Abstract}

\section{Background}

Leonuri Herba (Yimucao) is a very commonly Chinese herbs for treating menstrual and maternal diseases for thousands of years in China. However, the herb collected in different origins was easily found in the markets which induce the unstable quality for clinic use. In this study, a comprehensive strategy of using multiple chromatographic analysis and chemometric analysis was firstly investigated for chemical discrimination of Leonuri Herba from different geographical origins.

\section{Methods}

UHPLC-QTOF-MS/MS was applied to identify the peaks of Leonuri Herba and chemical fingerprints were established in 30 batches from different geographical origins. Meanwhile, dissimilarities of chemical compositions among different origins were further investigated by principal component analysis and cluster analysis.

\section{Results}

A total of 49 chromatographic peaks of Leonuri Herba were unequivocally or tentatively identified by UHPLC-QTOF-MS/MS. Leonuri Herba were classified into four categories, and eight major compounds detected could be used as chemical markers for discrimination. Also, the eight components, including leonurine, 4',5-dihydroxy-7-methoxyflavone, rutin, hyperoside, apigenin, quercetin, kaempferol and salicylic acid, were simultaneously quantified using the extracting ion mode of UHPLC-QTOF-MS/MS.

\section{Conclusion}

This systematic information could ensure Leonuri Herba with well-controlled quality and safe use in clinic. This study could also provide a research model for further study of other Chinese Materia Medica.

\section{Background}

Leonuri Herba (Yimucao) is the aerial part of Leonurus japonicus Houtt., which is a very commonly used herb for treating menstrual and maternal diseases. It has been used for thousands of years in Chinese Medicine, and it is recognized to be a non-toxic herb [1]. Leonurus japonicus Houtt. grows on wastelands of mountains and plains, rand, grasslands and streamsides. It distributes throughout China. The medicinal materials are mainly produced in Henan (Songxian and Luanzhou), Anhui (Liuan and Bengbu), Sichuan (Wenjiang), Jiangsu (Nanjing), Zhejiang (Fenghua)[2]. Besides, it is also native to other countries such as Europe, North America, Japan, Malaysia, etc. [3]. According to Chinese Pharmacopoeia[4], the dried herb is collected in summer before flowering and dried under the sun to obtain Herba Leonuri. However, the herb collected in different stages with the varied proportion of leaves and stems was easily found in the markets which induce the unstable quality for clinic use. Thus, the quality of this traditional Chinese Materia Medica has already attracted public concern. Leonuri Herba has plenty of pharmacological effects for treating human diseases [5], especially in gynecopathy [6], as well as other functions with its low toxic property[7]. Thus, it has been using for a long time as TCM. Besides, quite a lot of studies have been conducted by extracting its active components and investigate on their mechanisms [5].

Leonuri Herba is produced all over the country and it is not a geo-authentic herbs (daodi yaochai). It is difficult to determine the quality of Leonuri Herba in different geographical origins. Furthermore, different harvesting period of Leonuri Herba is also one of the major factors affecting the quality. Nowadays, Hong Kong usually purchases Leonuri Herba at seedling stage while mainland China usually purchases the mature Leonuri Herba. These situations show the necessity and importance to clarify whether the seedling or the mature one is better and the preference of geographical origins that should be chosen. There are around 140 compounds discovered in Leonuri Herba, alkaloids, diterpenes and flavones are its main chemicals [1]. Apart from leonurine and stachydrine, the studies of other components such as diterpenes and flavones that monitoring the quality of Leonuri Herba is still deficient [3]. This leads to the significance of analyzing the quality of Leonuri Herba by other chemical components.

This study aims to use chromatographic analysis and chemometric analysis focus on investigating for chemical discrimination of Leonuri Herba from different geographical origins, so as to provide evidence for evaluating the quality of Leonuri Herba. The symbolic components in Leonuri Herba are the targets for enhancing the analysis methods of quality control. Combining principal component analysis and cluster analysis with UHPLC-QTOF-MS/MS is employed to assay the level of content in different growing stages and origins. 


\section{Materials And Methods}

\section{Herbal materials}

Thirty batches of leonuri herba were acquired for this study. Of these, ten batches were obtained from the Hong Kong medicine market, other batches were purchased directly from certified production regions in China, as specified in Table 1. Thirty batches of leonuri herba were all authenticated by Prof. Zhongzhen Zhao from the School of Chinese Medicine (SCM), Hong Kong Baptist University (HKBU). Samples were dried, ground, then sifted through a 60-mesh sieve. Voucher specimens were deposited in SCM of HKBU (Additional file 1).

\section{Instrument, Chemicals and reagents}

Chemical markers of leonurine, rutin, 4',5-dihydroxy-7-methoxyflavone, hyperoside, salicylic acid, kaempferol were obtained from Shanghai Tauto Biotech Co. Ltd. (Shanghai, China). Chemical marker of apigenin was purchased from Chengdu Mansite Pharmacetical Co. Ltd. (Sichuan, China). Chemical marker of quercetin was obtained from the National Institute of Control of Pharmaceutical and Biological Products (Beijing, China). The purity of each chemical marker was above 95\%. Methanol and acetonitrile for UHPLC-QTOFMS/MS analysis were obtained from Merck (Darmstadt, Germany). Ultrapure water was prepared by a Milli-Q water purification system (Millipore, Bedford, MA, USA).

The analyses were performed on UHPLC (Agilent Technologies Inc., Palo Alto, CA, USA), Agilent 6540 ultra-high definition accurate mass quadrupole time-of-flight spectrometer (Agilent Technologies Inc., Wilmington, DE, USA).

\section{Sample Extraction}

The accurately weighed ground samples $(0.5 \mathrm{~g})$ was extracted with $5 \mathrm{~mL}$ of methanol for $60 \mathrm{~min}$ at $60^{\circ} \mathrm{C}$ in an ultrasonic water bath $(300 \mathrm{~W})$, and then cooled to room temperature. After compensating the lost weight of methanol, the extracted solution was filtered through a $0.22 \mu \mathrm{m}$ PTFE syringe filter UHPLC fingerprint and identification analysis by UHPLC-PDA-QTOF-MS/MS [8].

\section{UHPLC-QTOF-MS/MS Identification}

According to the research reports on the chemical components of Leonuri Herba, 121 chemical compounds are collected from Leonuri Herba. Agilent's "Mass Hunter PCDL Manager" software is used to calculate the relatively molecular mass accurately and establish a database of known chemical components of Leonuri Herba.

\section{Chromatographic conditions:}

Waters ACQUITY UPLC® BEH-C18 analytical column (2.1 mm x $100 \mathrm{~mm}$, I.D. $1.7 \mu \mathrm{m})$; VanGuardTM BEH-C18 guard column (2.1 mm x 5

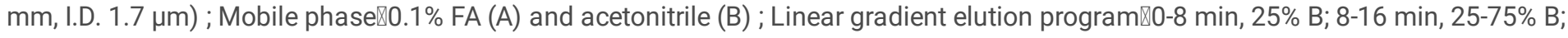

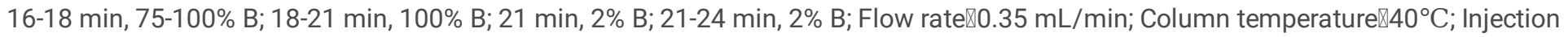
volume $22 \mu \mathrm{L}$.

\section{Mass spectrometry conditions:}

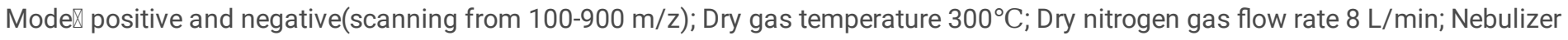
pressure 40 psi; Vcap 3500; Nozzle voltage $500 \mathrm{~V}$; Fragmentor voltage $120 \mathrm{~V}$. The mass spectrum was calibrated by Tune mix every time (positive mode, 118-1521 m/z; negative mode, 112-1634 m/z).

\section{Fingerprint similarity evaluation}

According to the UHPLC-MS/MS spectra of 30 samples, the common chromatographic fingerprint peaks and internal reference peaks contained in each batch of samples were confirmed. The Similarity evaluation system for chromatographic fingerprint of TCM was used to establish the fingerprint of 30 batches of Leonuri Herba. The similarity was calculated by the angle cosine method.

\section{Hierarchical clustering analysis and principal component analysis}

For HCA, the common fingerprint peak area of Leonuri Herba from different origins and batches are used as the source data of hierarchical clustering analysis. The hierarchical clustering algorithm in microarray analysis software (MeV 4.7.4) is used. For PCa, the 
common fingerprint peak area of Leonuri Herba fingerprints from different origins and batches are used as the source data of PCA by using factor analysis in SPSS 20.0(SPSS Corporation, Armonk, NY, USA).

\section{Quantitative analysis}

The accurately weighed ground samples of 29 batches $(0.5 \mathrm{~g})$ were respectively extracted with methanol $(2.5 \mathrm{~mL})$ for $60 \mathrm{~min}$, and then cooled to $25^{\circ} \mathrm{C}$. After centrifugation at $3,500 \mathrm{~g}$ for $10 \mathrm{~min}$, the supernatant was transferred to a $10 \mathrm{~mL}$ volumetric flask. This process was repeated twice and then the volume was adjusted to the calibration mark with methanol. The extracted solution was filtered through a $0.22 \mu \mathrm{m}$ PTFE syringe filter before analysis. The accurately weighed markers: $2.0 \mathrm{mg}$ of leonurine and rutin; $1.5 \mathrm{mg}$ of hyperoside and apigenin; $1.0 \mathrm{mg}$ of 4',5-dihydroxy-7-methoxyflavone, salicylic acid, kaempferol and quercetin. Each of them placed in a $5 \mathrm{~mL}$ volumetric flask and then the volume was adjusted to the calibration mark with methanol. Then the markers with $5.0 \mathrm{~mL}$ of leonurine, $6.25 \mathrm{~mL}$ of rutin, $3.75 \mathrm{~mL}$ of hyperoside, $2.0 \mathrm{~mL}$ of salicylic acid, $3.0 \mathrm{~mL}$ of quercetin, $1.25 \mathrm{~mL}$ of apigenin, $1.25 \mathrm{~mL}$ of kaempferol and $2.5 \mathrm{~mL}$ of 4',5-dihydroxy-7-methoxyflavone were accurately weighed and put them into a $25 \mathrm{~mL}$ measuring cylinder. The mixed marker solution could be obtained (leonurine: $0.084 \mathrm{mg} / \mathrm{mL}$; rutin: $0.10 \mathrm{mg} / \mathrm{mL}$, hyperoside: $0.048 \mathrm{mg} / \mathrm{mL}$, salicylic acid: 0.016 $\mathrm{mg} / \mathrm{mL}$, quercetin: $0.024 \mathrm{mg} / \mathrm{mL}$, Apigenin: $0.01 \mathrm{mg} / \mathrm{mL}$, kaempferol: $0.01 \mathrm{mg} / \mathrm{mL}$ and 4',5-dihydroxy-7-methoxyflavone: $0.02 \mathrm{mg} / \mathrm{mL}$ ).

\section{Statistical analysis}

Peaks above the $\mathrm{S} / \mathrm{N}$ ratio of the chromatogram were labeled and manually integrated using version 7.2 of the Chromeleon Chromatography Data System software (Thermo Fisher Scientific) to distinguish between the different batches. Summary data were expressed as the mean \pm standard deviation (SD) for $n=3-7$.

\section{Results And Discussion}

\section{Components authentication}

Figure 1A shows the Base peak chromatogram (BPC) of Leonuri Herba in negative mode. According to TR, Mass, (-)-ESI-MS/MS Fragment lons and compared with the reference and standards, 49 components were identified or preliminarily identified. There were 2 alkaloids, 18 flavonoids, 7 Terpenoids, 8 aromatic acids and 14 other classes (Table 2).

\section{Fingerprint analysis}

According to the UHPLC-MS/MS spectrum of 30 batches of samples, the chromatographic peaks could be showed within 24 minutes. Thirty-three of them were the common peaks to each batch of samples (Table 3). The total peak area of each batch of samples accounted for more than $85 \%$ of the total peak area and the reproducibility was good, which fulfilled the requirements of fingerprints. Thus, they were determined as a common fingerprint peak. The common fingerprint peak could be determined by the standard retention time. When the retention time was $6.53 \mathrm{~min}$, it was leonurine (Figure 1B). Since the peak area of leonurine was relatively big, the peak time was moderate and the shape was good, it was selected as the reference peak. Using Similarity Evaluation System for Chromatographic Fingerprint of Traditional Chinese Medicine (2004A edition). Thirty batches of Leonuri Herba from different origins were introduced (Figure 2) and the time width was $0.1 \mathrm{~min}$, gaining the control fingerprint by median generation method. The similarity of 30 batches of samples was calculated by the angle cosine method. The result showed the similarity between each fingerprint and the control fingerprint was less than 0.90 , indicating there was a big difference in each origin including Hubei, Guangdong, Henan, Anhui, Yunnan, Zhejiang and Sichuan. Thus, principal component and hierarchical cluster analysis should be further carried put to clarify the relationship between origins and quality.

\section{Results of hierarchical clustering analysis (HCA)}

The analysis showed the samples could be roughly clustered into Henan and Anhui as a big group; Yunnan and Sichuan as a big group; Guangdong and Hubei (at seedling stage) as a big group; Hubei (at mature stage) as a small group. This proved the components were similar if the origins are close. However, many factors such as harvest time, proportion of medical parts, soil, environment, and water were different, resulting in significant differences in chemical components of Leonuri Herba in different counties but same provinces. Thus, it is necessary to find quality markers in different origins to clarify the relationship between habitat and quality. From the chemical composition clustering analysis, as shown in Figure 3 , the first component was leonurine. The second and third classes were quercetin3-0-robinoside, rutin and 4',5-dihydroxy-7-methoxyflavone. The fourth class was quercetin-3-0- $\beta$-D-glucopyranoside, tiliroside and hyperoside. The fifth class was lavandulifolioside, salicylic acid, syringic acid and 2"'-syringylrutin. The sixth to eighth classes were 
daidzein, phytol, and apigenin. Other classes also included kaempferol, quercetin, tryptophan, 7a(H)-eudesmane-4,11(12)-diene-3-one$2 \beta$-hydroxy-13- $\beta$-D- glucopyranoside, etc. These different classes of components could be used to distinguish the quality of Leonuri Herba and as a basis for quantitative analysis.

Leonurine(C1), 4',5-dihydroxy-7-methoxyflavone(C3), rutin (C4), hyperoside(C11), apigenin(C15), quercetin(C16), kaempferol (C17) and salicylic acid (C30) were selected for further quantitative analysis of the indicator components.

\section{Results of principal component analysis[PCA $\square$}

The common fingerprint peak area of Leonuri Herba fingerprints from different origins and batches were used as the source data of PCA by using factor analysis in SPSS 20.0. The results of SPSS analysis indicated that the first principal component should integrate the information of $\mathrm{C} 1, \mathrm{C} 2, \mathrm{C} 3, \mathrm{C} 18, \mathrm{C} 21, \mathrm{C} 28, \mathrm{C} 29, \mathrm{C} 30$ compounds. Thus, the chemical composition differences of different origins and batches of Leonuri Herba were mainly reflected to these chemical components. The results showed that the content of C1 (Leonurine), C3 (4',5-dihydroxy-7-methoxyflavone) and C30 (Salicylic acid) in Henan samples is higher, which was consistent with the cluster analysis results. The matrix coefficient of main components 1-8 in Leonuri Herba are shown in Figure 4. In Figure 4A, PCA divided Leonuri Herba from different origins into four parts: Henan, Anhui as a large category; Yunnan, Sichuan as a large category; Guangdong, Hubei (at seedling stage) as a large category; Hubei (at mature stage) as a large category, which were consistent with the results of cluster analysis, verifying the reliability of cluster analysis. Interestingly, these four groups were highly consistent with the collection locations of these samples (Figure 4B), which demonstrated that the chemical components of different samples are heavily influenced by growing area.

\section{Comprehensive evaluation analysis}

The relationship formula between the principal component load matrix $U$, the factor load matrix $A$ and the eigenvalue $\lambda$ was $U_{i}=A / S Q R T$ $\left(\lambda_{\mathrm{i}}\right)$. By calculating the variables, eight eigenvectors U1-8 were obtained, and the expressions of the 8 principal components could be obtained, as follows.

$Y_{1}=0.226 X_{1}+0.239 X_{2}+0.229 X_{3}-0.045 X_{4}+0.213 X_{5}+0.161 X_{6}+0.215 X_{7}+0.145 X_{8}+0.189 X_{9}+0.147 X_{10}+0.219 X_{11}+0.182 X_{12}-$ $0.055 \mathrm{X}_{13}+0.223 \mathrm{X}_{14^{-}}$ $0.053 X_{15}+0.058 X_{16}+0.040 X_{17}+0.252 X_{18}+0.192 X_{19}+0.183 X_{20}+0.246 X_{21}+0.087 X_{22}+0.213 X_{23}+0.152 X_{24}+0.022 X_{25}+0.004 X_{26^{-}}$ $0.061 \mathrm{X}_{27}+0.243 \mathrm{X}_{28}+0.234 \mathrm{X}_{29}+0.276 \mathrm{X}_{30}+0.190 \mathrm{X}_{31}$

$Y_{2}=0.023 X_{1}-0.109 X_{2}+0.122 X_{3}+0.315 X_{4}+0.157 X_{5}+0.311 X_{6}+0.117 X_{7}+0.182 X_{8}+0.200 X_{9}+0.293 X_{10}+0.198 X_{11}+0.205 X_{12^{-}}-0.100 X_{13^{-}}$

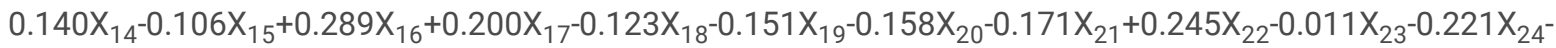
$0.085 X_{25}+0.153 X_{26}+0.053 X_{27}-0.217 X_{28}-0.167 X_{29}-0.139 X_{30}-0.069 X_{31}$

$Y_{3}=0.046 X_{1}-0.014 X_{2}+0.195 X_{3}-0.065 X_{4}-0.161 X_{5}+0.101 X_{6}-0.277 X_{7}-0.090 X_{8}-0.145 X_{9}-0.212 X_{10}-0.241 X_{11}-0.275 X_{12}+0.102 X_{13}+0.111 X_{14}$ $0.158 \mathrm{X}_{15}+0.274 \mathrm{X}_{16}+0.311 \mathrm{X}_{17^{-}}-0.021 \mathrm{X}_{18^{-}}-0.007 \mathrm{X}_{19}+0.225 \mathrm{X}_{20}+0.078 \mathrm{X}_{21}+0.275 \mathrm{X}_{22}+0.150 \mathrm{X}_{23^{3}}-0.170 \mathrm{X}_{24^{-}}$

$0.147 X_{25}+0.335 X_{26}+0.167 X_{27}+0.051 X_{28}-0.049 X_{29}+0.088 X_{30}+0.236 X_{31}$

$Y_{4}=-0.126 X_{1}-0.166 X_{2}+0.242 X_{3}-0.090 X_{4}-0.152 X_{5}+0.157 X_{6}+0.139 X_{7}+0.375 X_{8}-0.155 X_{9}+0.037 X_{10}-0.055 X_{11}-0.170 X_{12}+0.367 X_{13}-0.007 X_{14}$ $0.099 X_{15}+0.012 X_{16}+0.117 X_{17}+0.083 X_{18}+0.226 X_{19}-0.160 X_{20}+0.014 X_{21}+0.070 X_{22}-0.192 X_{23}+0.039 X_{24}+0.550 X_{25}+0.000 X_{26^{-}}$ $0.024 \mathrm{X}_{27}+0.007 \mathrm{X}_{28}+0.069 \mathrm{X}_{29}+0.012 \mathrm{X}_{30}-0.180 \mathrm{X}_{31}$

$Y_{5}=0.172 X_{1}-0.188 X_{2}+0.038 X_{3}-0.100 X_{4}+0.208 X_{5}+0.017 X_{6}-0.017 X_{7}-0.204 X_{8}+0.068 X_{9}+0.010 X_{10^{-}}$ $0.020 \mathrm{X}_{11}+0.137 \mathrm{X}_{12}+0.433 \mathrm{X}_{13}+0.210 \mathrm{X}_{14}+0.313 \mathrm{X}_{15}+0.044 \mathrm{X}_{16}+0.110 \mathrm{X}_{17}+0.174 \mathrm{X}_{18^{-}}-0.114 \mathrm{X}_{19}-0.168 \mathrm{X}_{20}-0.253 \mathrm{X}_{21^{-}}-0.097 \mathrm{X}_{22^{-}}$ $0.221 \mathrm{X}_{23}+0.259 \mathrm{X}_{24}-0.210 \mathrm{X}_{25}+0.318 \mathrm{X}_{26}+0.138 \mathrm{X}_{27}-0.006 \mathrm{X}_{28}+0.168 \mathrm{X}_{29}+0.055 \mathrm{X}_{30}-0.120 \mathrm{X}_{31}$

$\mathrm{Y}_{6}=0.181 \mathrm{X}_{1}+0.190 \mathrm{X}_{2}+0.098 \mathrm{X}_{3}+0.087 \mathrm{X}_{4}-0.138 \mathrm{X}_{5}-0.016 \mathrm{X}_{6}-0.003 \mathrm{X}_{7}-0.135 \mathrm{X}_{8}-0.066 \mathrm{X}_{9}-0.029 \mathrm{X}_{10}-0.070 \mathrm{X}_{11}+0.003 \mathrm{X}_{12^{-}}-0.062 \mathrm{X}_{13^{-}}$ $0.229 \mathrm{X}_{14}+0.043 \mathrm{X}_{15}+0.165 \mathrm{X}_{16^{-}}-0.115 \mathrm{X}_{17^{-}}-0.165 \mathrm{X}_{18}+0.010 \mathrm{X}_{19^{-}}-0.213 \mathrm{X}_{20^{-}}-0.080 \mathrm{X}_{21}+0.243 \mathrm{X}_{22}+0.271 \mathrm{X}_{23}+0.309 \mathrm{X}_{24}+0.073 \mathrm{X}_{25^{-}}$ $0.204 \mathrm{X}_{26}+0.516 \mathrm{X}_{27}+0.096 \mathrm{X}_{28}+0.133 \mathrm{X}_{29}+0.121 \mathrm{X}_{30}-0.322 \mathrm{X}_{31}$

$Y_{7}=-0.146 X_{1}-0.062 X_{2}-0.083 X_{3}-0.053 X_{4}+0.137 X_{5}+0.004 X_{6}-0.163 X_{7}+0.207 X_{8}+0.134 X_{9}+0.166 X_{10}-0.082 X_{11}-0.006 X_{12}+0.139 X_{13^{-}}$ $0.286 X_{14}+0.644 X_{15}+0.139 X_{16^{-}}-0.095 X_{17}-0.201 X_{18}+0.316 X_{19}+0.208 X_{20}+0.213 X_{21^{-}}-0.002 X_{22}+0.149 X_{23^{-}}$ 
$0.049 \mathrm{X}_{24}+0.017 \mathrm{X}_{25}+0.096 \mathrm{X}_{26}+0.084 \mathrm{X}_{27}-0.021 \mathrm{X}_{28}-0.052 \mathrm{X}_{29}-0.030 \mathrm{X}_{30}+0.081 \mathrm{X}_{31}$

$Y_{8}=0.187 X_{1}+0.358 X_{2}+0.062 X_{3}+0.043 X_{4}-0.072 X_{5}-0.157 X_{6}+0.155 X_{7}-0.061 X_{8}-0.020 X_{9}-0.043 X_{10}-0.036 X_{11^{-}}$

$0.040 \mathrm{X}_{12}+0.182 \mathrm{X}_{13}+0.041 \mathrm{X}_{14}+0.216 \mathrm{X}_{15}-0.034 \mathrm{X}_{16}+0.296 \mathrm{X}_{17}-0.174 \mathrm{X}_{18^{-}}$

$0.186 \mathrm{X}_{19}+0.015 \mathrm{X}_{20}+0.012 \mathrm{X}_{21}+0.065 \mathrm{X}_{22}+0.321 \mathrm{X}_{23}+0.158 \mathrm{X}_{24}+0.138 \mathrm{X}_{25}+0.101 \mathrm{X}_{26}-0.502 \mathrm{X}_{27}-0.143 \mathrm{X}_{28}-0.222 \mathrm{X}_{29}-0.106 \mathrm{X}_{30}-0.201 \mathrm{X}_{31}$

Normalizing the original variables and using SPSS to compute variables and calculate the principal components $Y 1, \mathrm{Y} 2, \mathrm{Y} 3, \mathrm{Y} 4, \mathrm{Y} 5, \mathrm{Y} 6$, $Y 7$ and Y8. Taking the variance contribution rate corresponding to each principal component as the weight, the principal component scores and the corresponding weights were linearly weighted to construct a comprehensive evaluation function of different habitats and batches of Leonuri Herba :

$Y=0.301 Y_{1}+0.192 Y_{2}+0.131 Y_{3}+0.078 Y_{4}+0.052 Y_{5}+0.043 Y_{6}+0.038 Y_{7}+0.034 Y_{8}$

The comprehensive evaluation scores of Leonuri Herba from different origins and batches were calculated form the above formula are shown in Table 4. The higher of the score, the better of the sample quality of origins and batch. The comprehensive score was greater than 0 . The results showed that batch $S 8$ (from Hubei at seedling stage) had the highest comprehensive score, followed by batch $S 4$ (from Guangdong at seedling stage), S15 (Henan) S10 (from Hubei at seedling stage) and S13 (Henan). The above results showed that the quality of three batches at seedling stage was better than the others. The quality of Leonuri Herba produced in Henan is relatively good when compare to other origins.

\section{Result of Quantitative Analysis}

The LOD was calculated according to the signal-to-noise ratio of 3:1; the LOQ was calculated according to the signal-to-noise ratio of 10:1, and the results were shown in (Additional file 20Table S1). The precision test results showed that the precision of the instrument was good; the stability test results showed that the test solution had a good stability within 24 hours after preparation; the repeatability test results showed that the method had a good repeatability; the results of the sample recovery rate showed that the accuracy was good (Additional file 30Table S2).. The results of 30 batches of Leonuri Herba from different origins are shown in Table 5. The detailed content trends of eight analytes in the 30 samples from different origins are exhibited in Figure 5. In Figure 5A, the results showed that YMC from Henan had the highest content in Leonurine (C1), 4',5-dihydroxy-7-methoxyflavone(C3), rutin (C4) and hyperoside(C11). However, the content of rutin(C4) in Zhejiang was the highest. For apigenin(C15), quercetin(C16), kaempferol (C17) and salicylic acid (C30), Hubei, Henan and Sichuan had similar result (Figure 5B). By adding all the eight analytes together, the total content of Henan is the highest (Figure 5C).

In summary, the quality of Leonuri Herba at seedling stage is better than the mature ones. Apart from the quality of medicinal part, Leonuri Herba from different origins are mainly clustered into four categories: Henan and Anhui are grouped together; Yunnan and Sichuan are grouped together; Guangdong and Hubei (at seedlings stage) are grouped together; Hubei (at mature stage) is grouped as one type. The comprehensive evaluation analysis showed that the quality of Leonuri Herba at seedling stage was good. And the quality of Leonuri Herba in Henan was relatively good when compare to other origins. However, the quality difference between stems and leaves from different origins and different growing stage is not very clear. Further studies should be conducted to address this issue. Laser microdissection combined with chromatographic analysis could be one of the powerful tool to investigate the chemical composition distribution and change in different growing stages of Leonuri Herba. This may also help to unify the standard of Leonuri Herba so as to decrease the confusion in markets.

\section{Conclusion}

Based on the above trials, the fingerprints of 30 batches of Leonuri Herba in different origins were established, 33 chromatographic fingerprint peaks were confirmed. In this study, we developed an accurate, fast, stable, and reproducible content determination method for these eight components: leonurine, 4', 5-dihydroxy-7-methoxyflavone, rutin, hyperoside, apigenin, quercetin, kaempferol and salicylic acid by UHPLC-QTOF-MS/MS. The content determination has realized the qualitative and quantitative analysis of the Leonuri Herba under the same chromatographic conditions and provided a simple and rapid analysis method for the quality control of Leonuri Herba.

\section{Abbreviations}


BPC: Base Peak Chromatogram; LOD: Limit of Detection; LOQ: Limit of Quantification; MF: Molecular Formula; MS: Mass Spectrometry; PCA: Principal Component Analysis; TCM: Traditional Chinese medicine; UHPLC: Ultra-high performance liquid chromatography

\section{Declarations}

\section{Ethics approval and consent to participate}

Not applicable

\section{Consent to publish}

Not applicable

\section{Availability of data and materials}

The data used to support the current study are available from the corresponding author on reasonable request.

\section{Competing interests}

The authors declare that they have no competing interests.

\section{Funding}

This work was supported by the Research Grants Council (Project No. 12102217 and 12103919).

\section{Authors' contributions}

Zhongzhen Zhao and Kelly Yinching Lam were in charge of idea and concept of the paper; Kelly Yinching Lam, Yinghao Wang and Tszking Lam performed the experiment; Kelly Yinching Lam, Yinghao Wang processed the data and wrote the paper. Chuenfai Ku and Wingping Yeung were in charge of sample collection; Zhongzhen Zhao acquired funding for the research. All authors read and approved the final manuscript.

\section{Acknowledgements}

We thank Alan Ho from the School of Chinese Medicine, Hong Kong Baptist University, for his technical assistance.

\section{References}

1. Shang, X.; Pan, H.; Wang, X.; He, H., \& Li, M. Leonurus japonicus Houtt.: ethnopharmacology, phytochemistry and pharmacology of an important traditional Chinese medicine. Journal of Ethnopharmacology 2014, 152(1), 14-32.

2. Dong, S.; He, J.; Hou, H.; Shuai, Y.; Wang, Q.; Yang, W. \& Liu, R. Quality assessment of Herba Leonuri based on the analysis of multiple components using normal-and reversed-phase chromatographic methods. Journal of separation science 2017, 40(23), 4482-4494.

3. Zhu, Y. Z.; Wu, W.; Zhu, Q. \& Liu, X. Discovery of Leonuri and therapeutical applications: from bench to bedside. Pharmacology \& therapeutics 2018, 188, 26-35.

4. Chinese Pharmacopoeia Commission. The Pharmacopoeia of the People's Republic of China, 2020 ed.; China Medical Science Press: Beijing, China, 2020.

5. Wang, C.; Lv, X.; Liu, W.; Liu, S. \& Sun, Z. Uncovering the pharmacological mechanism of motherwort (Leonurus japonicus Houtt.) for treating menstrual disorders: A systems pharmacology approach. Computational Biology and Chemistry 2020, 107384.

6. Liu, J.; Peng, C.; Zhou, Q. M.; Guo, L.; Liu, Z. H. \& Xiong, L. Alkaloids and flavonoid glycosides from the aerial parts of Leonurus japonicus and their opposite effects on uterine smooth muscle. Phytochemistry 2018, 145, 128-136.

7. He, Y. L.; Shi, J. Y.; Peng, C.; Hu, L. J.; Liu, J.; Zhou, Q. M. \& Xiong, L. Angiogenic effect of motherwort (Leonurus japonicus) alkaloids and toxicity of motherwort essential oil on zebrafish embryos. Fitoterapia 2018, 128, 36-42.

8. Zhu, L. X.; Xu, J.; Wang, R. J.; Li, H. X.; Tan, Y. Z.; Chen, H. B. \& Zhao, Z. Z. Correlation between quality and geographical origins of Poria cocos revealed by qualitative fingerprint profiling and quantitative determination of triterpenoid acids. Molecules 2018, 23(9), 
2200 .

9. Liu, J.; Peng, C.; Zhou, Q. M.; Guo, L.; Liu, Z. H. \& Xiong, L. Alkaloids and flavonoid glycosides from the aerial parts of Leonurus japonicus and their opposite effects on uterine smooth muscle. Phytochemistry 2018, 145, 128-136.

10. Wojtyniak, K.; Szymański, M. \& Matławska, I. Leonurus cardiaca L.(motherwort): a review of its phytochemistry and pharmacology. Phytotherapy Research 2013, 27(8), 1115-1120.

11. Xiong, L.; Peng, C.; Zhou, Q. M.; Wan, F.; Xie, X. F.; Guo, L. \& Dai, O. Chemical composition and antibacterial activity of essential oils from different parts of Leonurus japonicus Houtt. Molecules 2013, 18(1), 963-973.

12. Kuchta, K.; Ortwein, J.; Savtschenko, A.; Briel, D.; Volk, R. B. \& Rauwald, H. W. Leonurus cardiaca, L. Japonicus, Leonotis leonurus: Quantitative HPLC and instrumental HPTLC determination of fourteen phenolics. Planta Medica 2012, 78(11), PJ50.

13. Li, Y.; Chen, Z.; Feng, Z.; Yang, Y.; Jiang, J. \& Zhang, P. Hepatoprotective glycosides from Leonurus japonicus Houtt. Carbohydrate research 2012, 348, 42-46.

14. Tan, Y. J.; Zhou, G. S.; Guo, S.; Yan, H.; Zhang, J.; Zhu, Z. H. \& Duan, J. A. Simultaneous optimization of ultrasonic-assisted extraction of antioxidant and anticoagulation activities of compounds from Leonurus japonicus Houtt. by response surface methodology. RSC advances 2018, 8(71), 40748-40759.

15. Wagner, H.; Bauer, R.; Melchart, D.; Xiao, P. G. \& Staudinger, A. Herba Leonuri-Yimucao. In Chromatographic Fingerprint Analysis of Herbal Medicines 2011(pp. 707-717). Springer, Vienna.

16. Chen, Z.; Wu, J. B.; Liao, X. J.; Yang, W. \& Song, K. Development and validation of an UPLC-DAD-MS method for the determination of leonurine in Chinese motherwort (Leonurus japonicus). Journal of chromatographic science 2010, 48(10), 802-806.

17. Deng, S.; Wang, T.; Wu, C. H.; Qu, L., Han, L. F. \& Zhang, Y. Isolation and identification of constituents from Leonurus japonicus. Chin. J. Med. Chem. 2013, 23, 209-212.

18. Xiong, L.; Zhou, Q. M.; Peng, C.; Xie, X. F.; Guo, L.; Li, X. H. \& Dai, O. Sesquiterpenoids from the herb of Leonurus japonicus. Molecules 2013, 18(5), 5051-5058.

19. Seo, H. K.; Kim, J. S. \& Kang, S. S. Labdane diterpenes and flavonoids from Leonurus japonicus. Helvetica Chimica Acta 2010, 93(10), 2045-2051.

20. Chang, J. M.; Shen, C. C.; Huang, Y. L.;Shieh, B. J. \& Chen, C. C. Two new glycosides from Leonurus japonicus. Journal of Asian natural products research 2010, 12(9), 740-744.

21. Garran, T. A.; Ji, R., Chen; J. L.; Xie, D.; Guo, L.; \& Huang, L. Q. Elucidation of metabolite isomers of Leonurus japonicus and Leonurus cardiaca using discriminating metabolite isomerism strategy based on ultra-high performance liquid chromatography tandem quadrupole time-of-flight mass spectrometry. Journal of Chromatography A 2019, 1598, 141-153.

22. Kuchta, K.; Ortwein, J.; Savtschenko, A.; Briel, D.; Volk, R. B. \& Rauwald, H. W. Leonurus cardiaca, L. Japonicus, Leonotis leonurus: Quantitative HPLC and instrumental HPTLC determination of fourteen phenolics. Planta Medica 2012, 78(11), PJ50.

23. Miao, L. L.; Zhou, Q. M.; Peng, C.; Liu, Z. H. \& Xiong, L. Leonurus japonicus (Chinese motherwort), an excellent traditional medicine for obstetrical and gynecological diseases: A comprehensive overview. Biomedicine \& Pharmacotherapy 2019, 117, 109060.

\section{Tables}


Table 1

The batch number and geographic habitats of 30 samples of Leonuri Herba

\begin{tabular}{|c|c|c|c|c|c|}
\hline Batch no. & Sample code & Name & Habitats & Stem/\% & Leaf/\% \\
\hline S1 & HB1 & Leonuri Herba (mature) & Hubei, China & 67.90 & 32.10 \\
\hline S2 & HB2 & Leonuri Herba & Hubei, China & 20.25 & 79.75 \\
\hline S3 & HB3 & Leonuri Herba (mature) & Hubei, China & 69.48 & 30.52 \\
\hline S4 & GD1 & Leonuri Herba (seedling) & Guangdong, China & 30.05 & 69.95 \\
\hline S5 & HB4 & Leonuri Herba & Hubei, China & 23.08 & 76.92 \\
\hline S6 & GD2 & Leonuri Herba & Guangdong, China & 18.44 & 81.56 \\
\hline S7 & GD3 & Leonuri Herba & Guangdong, China & 29.68 & 70.32 \\
\hline S8 & HB5 & Leonuri Herba (seedling) & Hubei, China & 34.24 & 65.76 \\
\hline S9 & HB6 & Leonuri Herba & Hubei, China & 31.06 & 68.94 \\
\hline S10 & HB7 & Leonuri Herba (seedling) & Hubei, China & 25.54 & 74.46 \\
\hline S11 & HN1 & Leonuri Herba & Henan, China & 62.26 & 37.74 \\
\hline S12 & HN2 & Leonuri Herba & Henan, China & 61.68 & 38.32 \\
\hline S13 & HN3 & Leonuri Herba & Henan, China & 52.12 & 47.88 \\
\hline S14 & HN4 & Leonuri Herba & Henan, China & 66.87 & 33.13 \\
\hline S15 & HN5 & Leonuri Herba & Henan, China & 63.37 & 36.63 \\
\hline S16 & $\mathrm{AH} 1$ & Leonuri Herba & Anhui, China & 63.29 & 36.71 \\
\hline S17 & $\mathrm{AH} 2$ & Leonuri Herba & Anhui, China & 53.69 & 46.31 \\
\hline S18 & $\mathrm{AH} 3$ & Leonuri Herba & Anhui, China & 66.13 & 33.87 \\
\hline S19 & $\mathrm{AH} 4$ & Leonuri Herba & Anhui, China & 38.12 & 61.88 \\
\hline S20 & YN1 & Leonuri Herba & Yunnan, China & 58.84 & 41.16 \\
\hline S21 & YN2 & Leonuri Herba & Yunnan, China & 47.32 & 52.68 \\
\hline S22 & YN3 & Leonuri Herba & Yunnan, China & 53.26 & 46.74 \\
\hline S23 & YN4 & Leonuri Herba & Yunnan, China & 56.73 & 43.27 \\
\hline S24 & ZJ1 & Leonuri Herba & Zhejiang, China & 40.64 & 59.36 \\
\hline S25 & ZJ2 & Leonuri Herba & Zhejiang, China & 56.63 & 43.37 \\
\hline S26 & SC1 & Leonuri Herba & Sichuan, China & 48.23 & 51.77 \\
\hline S27 & SC2 & Leonuri Herba & Sichuan, China & 52.92 & 47.08 \\
\hline S28 & SC3 & Leonuri Herba & Sichuan, China & 72.61 & 27.39 \\
\hline S29 & SC4 & Leonuri Herba & Sichuan, China & 57.52 & 42.48 \\
\hline S30 & ZJ3 & Leonuri Herba & Zhejiang, China & 40.45 & 59.55 \\
\hline
\end{tabular}


Table 2

Structural information of compounds characterized in the Leonuri Herba by negative-UHPLC-QTOF-MS/MS

\begin{tabular}{|c|c|c|c|c|c|c|c|c|}
\hline & $t_{R}(\min )$ & MF & Product ion & Mass & Mass(Tgt) & Diff(ppm) & $\begin{array}{l}(-)-\text {-ESI- } \\
\text { MS/MS } \\
\text { Fragment } \\
\text { lons } \\
(\mathrm{m} / \mathrm{z})\end{array}$ & Identification [Reference] \\
\hline 1 & 2.630 & $\mathrm{C}_{9} \mathrm{H}_{11} \mathrm{NO}_{2}$ & {$[\mathrm{M}-\mathrm{H}]^{-}$} & 165.0797 & 165.0790 & 4.50 & 57.0355 & phenylalanine[9] \\
\hline 2 & 3.838 & $\mathrm{C}_{11} \mathrm{H}_{12} \mathrm{~N}_{2} \mathrm{O}_{2}$ & {$[\mathrm{M}+\mathrm{COOH}]^{-}$} & 204.0908 & 204.0899 & 4.43 & & tryptophan [9] \\
\hline 3 & 4.14 & $\mathrm{C}_{7} \mathrm{H}_{6} \mathrm{O}_{3}$ & {$[\mathrm{M}-\mathrm{H}]^{-}$} & 138.0324 & 138.0317 & 5.32 & & salicylic acid[10] \\
\hline 4 & 4.548 & $\mathrm{C}_{9} \mathrm{H}_{10} \mathrm{O}_{3}$ & {$[\mathrm{M}+\mathrm{COOH}]^{-}$} & 166.0640 & 166.0630 & 5.97 & $\begin{array}{l}\text { 150.0330, } \\
72.9938\end{array}$ & ethyl 4-hydroxybenzoate [11] \\
\hline 5 & 4.764 & $\mathrm{C}_{14} \mathrm{H}_{20} \mathrm{O}_{9}$ & {$[\mathrm{M}-\mathrm{H}]^{-}$} & 332.1118 & 332.1107 & 3.25 & $\begin{array}{l}\text { 316.0867, } \\
197.0473 \\
61.9892\end{array}$ & $\begin{array}{l}\text { 2,6-dimethoxy-4- } \\
\text { hydroxyphenol-1-O- } \beta-D- \\
\text { glucopyranoside [12] }\end{array}$ \\
\hline 6 & 4.989 & $\mathrm{C}_{27} \mathrm{H}_{42} \mathrm{O}_{17}$ & {$[\mathrm{M}-\mathrm{H}]^{-}$} & 638.2439 & 638.2422 & 2.60 & $\begin{array}{l}\text { 578.2197, } \\
461.2364, \\
255.2342 \\
89.025\end{array}$ & leonoside F [13] \\
\hline 7 & 5.223 & $\mathrm{C}_{7} \mathrm{H}_{6} \mathrm{O}_{2}$ & {$[\mathrm{M}-\mathrm{H}]^{-}$} & 122.0376 & 122.0368 & 6.49 & $\begin{array}{l}\text { 167.0335, } \\
108.0221\end{array}$ & benzoic acid [143] \\
\hline 8 & 5.340 & $\mathrm{C}_{8} \mathrm{H}_{8} \mathrm{O}_{3}$ & {$[\mathrm{M}+\mathrm{COOH}]^{-}$} & 152.0483 & 152.0473 & 6.41 & 123.0096 & vanillin [15] \\
\hline 9 & 5.341 & $\mathrm{C}_{9} \mathrm{H}_{10} \mathrm{O}_{5}$ & {$[\mathrm{M}-\mathrm{H}]^{-}$} & 198.0538 & 198.0528 & 5.02 & 123.0096 & syringic acid [14] \\
\hline 10 & 5.660 & $\mathrm{C}_{11} \mathrm{H}_{14} \mathrm{O}_{5}$ & {$[\mathrm{M}+\mathrm{COOH}]^{-}$} & 226.0859 & 226.0841 & 7.82 & $\begin{array}{l}256.0593 \\
123.0099 \\
59.0140\end{array}$ & $\begin{array}{l}\text { 3-hydroxyl-1-(4-hydroxy-3,5- } \\
\text { dimethoxyphenyl)-1- } \\
\text { propanone [1] }\end{array}$ \\
\hline 11 & 5.865 & $\mathrm{C}_{19} \mathrm{H}_{32} \mathrm{O}_{8}$ & {$[\mathrm{M}+\mathrm{COOH}]^{-}$} & 388.2109 & 388.2097 & 3.10 & $\begin{array}{l}\text { 401.1477, } \\
197.0454 \\
61.9893\end{array}$ & staphylionoside E [13] \\
\hline 12 & 6.533 & $\mathrm{C}_{8} \mathrm{H}_{8} \mathrm{O}_{4}$ & {$[\mathrm{M}-\mathrm{H}]^{-}$} & 168.0430 & 168.0423 & 4.45 & 108.0221 & vanillic acid [15] \\
\hline 13 & 6.542 & $\mathrm{C}_{7} \mathrm{H}_{6} \mathrm{O}_{2}$ & {$[\mathrm{M}-\mathrm{H}]^{-}$} & 122.0376 & 122.0368 & 6.51 & $\begin{array}{l}\text { 167.0335, } \\
108.0221\end{array}$ & 4-hydroxybenzaldehyde [12] \\
\hline 14 & 6.563 & $\mathrm{C}_{19} \mathrm{H}_{30} \mathrm{O}_{8}$ & {$[\mathrm{M}-\mathrm{H}]^{-}$} & 386.1948 & 386.1941 & 1.91 & $\begin{array}{l}\text { 189.1284, } \\
85.0309\end{array}$ & citroside A [13] \\
\hline 15 & 6.617 & $\mathrm{C}_{14} \mathrm{H}_{21} \mathrm{~N}_{3} \mathrm{O}_{5}$ & {$[\mathrm{M}-\mathrm{H}]^{-}$} & 311.1497 & 311.1481 & 4.96 & $\begin{array}{l}280.0956 \\
95.0148\end{array}$ & leonurine [16] \\
\hline 16 & 6.646 & $\mathrm{C}_{27} \mathrm{H}_{30} \mathrm{O}_{16}$ & {$[\mathrm{M}-\mathrm{H}]^{-}$} & 610.1556 & 610.1534 & 3.69 & $\begin{array}{l}447.0039 \\
300.0293 \\
151.0054\end{array}$ & quercetin-3-0-robinoside [17] \\
\hline 17 & 6.746 & $\mathrm{C}_{13} \mathrm{H}_{20} \mathrm{O}_{3}$ & {$[\mathrm{M}+\mathrm{COOH}]^{-}$} & 224.1426 & 224.1412 & 5.96 & & $\begin{array}{l}\text { (2S,5S)-2-hydroxy-2,6,10,10- } \\
\text { tetramethyl-1-oxaspiro- } \\
\text { [4.5]dex-6-en-8-one [1] }\end{array}$ \\
\hline 18 & 6.884 & $\mathrm{C}_{21} \mathrm{H}_{20} \mathrm{O}_{11}$ & {$[\mathrm{M}+\mathrm{COOH}]^{-}$} & 448.1027 & 448.1006 & 4.73 & $\begin{array}{l}284.0341 \\
61.9894\end{array}$ & $\begin{array}{l}\text { kaempferol-3-O-ß-D- } \\
\text { glucopyranoside [176] }\end{array}$ \\
\hline 19 & 6.968 & $\mathrm{C}_{27} \mathrm{H}_{30} \mathrm{O}_{16}$ & {$[\mathrm{M}-\mathrm{H}]^{-}$} & 610.1558 & 610.1534 & 3.94 & $\begin{array}{l}447.1139 \\
300.0294 \\
151.0055\end{array}$ & rutin [14] \\
\hline 20 & 6.997 & $\mathrm{C}_{10} \mathrm{H}_{10} \mathrm{O}_{4}$ & {$[\mathrm{M}-\mathrm{H}]^{-}$} & 194.0591 & 194.0579 & 5.97 & $\begin{array}{l}\text { 134.0387, } \\
58.0307\end{array}$ & trans-ferulic acid [12] \\
\hline 21 & 7.173 & $\mathrm{C}_{21} \mathrm{H}_{20} \mathrm{O}_{12}$ & {$[\mathrm{M}-\mathrm{H}]^{-}$} & 464.0978 & 464.0955 & 4.93 & $\begin{array}{l}300.0293 \\
61.9891\end{array}$ & hyperoside [17] \\
\hline
\end{tabular}




\begin{tabular}{|c|c|c|c|c|c|c|c|c|}
\hline & $t_{R}(\min )$ & MF & Product ion & Mass & Mass(Tgt) & Diff(ppm) & $\begin{array}{l}(-) \text {-ESI- } \\
\text { MS/MS } \\
\text { Fragment } \\
\text { lons } \\
(\mathrm{m} / \mathrm{z})\end{array}$ & Identification [Reference] \\
\hline 22 & 7.306 & $\mathrm{C}_{21} \mathrm{H}_{20} \mathrm{O}_{12}$ & {$[\mathrm{M}-\mathrm{H}]^{-}$} & 464.0976 & 464.0955 & 4.67 & $\begin{array}{l}300.0293 \\
151.0048 \\
61.9891\end{array}$ & $\begin{array}{l}\text { quercetin-3-O-ß-D- } \\
\text { glucopyranoside [17] }\end{array}$ \\
\hline 23 & 7.335 & $\mathrm{C}_{27} \mathrm{H}_{30} \mathrm{O}_{15}$ & {$[\mathrm{M}-\mathrm{H}]^{-}$} & 594.1607 & 594.1585 & 3.76 & $\begin{array}{l}\text { 463.0907, } \\
284.0344 \\
61.9891\end{array}$ & $\begin{array}{l}\text { kaempferol-3- } \\
\text { neohesperidoside [17] }\end{array}$ \\
\hline 24 & 7.494 & $\mathrm{C}_{34} \mathrm{H}_{44} \mathrm{O}_{19}$ & {$[\mathrm{M}-\mathrm{H}]^{-}$} & 756.2495 & 756.2477 & 2.37 & $\begin{array}{l}593.2095 \\
461.1679 \\
357.1262 \\
223.0608 \\
161.0254\end{array}$ & lavandulifolioside [13] \\
\hline 25 & 7.507 & $\mathrm{C}_{27} \mathrm{H}_{30} \mathrm{O}_{15}$ & {$[\mathrm{M}-\mathrm{H}]^{-}$} & 594.1607 & 594.1585 & 3.79 & $\begin{array}{l}387.1094 \\
284.0344 \\
61.9891\end{array}$ & $\begin{array}{l}\text { kaempferol-3-0- } \beta- \\
\text { robinobinoside [14] }\end{array}$ \\
\hline 26 & 7.832 & $\mathrm{C}_{27} \mathrm{H}_{30} \mathrm{O}_{15}$ & {$[\mathrm{M}-\mathrm{H}]^{-}$} & 594.1606 & 594.1585 & 3.56 & $\begin{array}{l}387.1094 \\
284.0344 \\
61.9891\end{array}$ & $\begin{array}{l}\text { kaempferol-3-0-rutinoside } \\
\text { [12] }\end{array}$ \\
\hline 27 & 8.083 & $\mathrm{C}_{21} \mathrm{H}_{20} \mathrm{O}_{11}$ & {$[\mathrm{M}-\mathrm{H}]^{-}$} & 448.1026 & 448.1006 & 4.66 & $\begin{array}{l}284.0341 \\
61.9894\end{array}$ & $\begin{array}{l}\text { kaempferol-3-O-B-D- } \\
\text { galactopyranoside [17] }\end{array}$ \\
\hline 28 & 8.493 & $\mathrm{C}_{15} \mathrm{H}_{20} \mathrm{O}_{3}$ & {$[\mathrm{M}-\mathrm{H}]^{-}$} & 248.1427 & 248.1412 & 6.00 & & arteannuin B [18] \\
\hline 29 & 8.903 & $\mathrm{C}_{36} \mathrm{H}_{38} \mathrm{O}_{20}$ & {$[\mathrm{M}-\mathrm{H}]^{-}$} & 790.1983 & 790.1956 & 3.42 & $\begin{array}{l}609.1483 \\
473.1289 \\
379.1785 \\
127.0408\end{array}$ & 2"'-syringylrutin [19] \\
\hline 30 & 9.635 & $\mathrm{C}_{12} \mathrm{H}_{20} \mathrm{O}_{5}$ & {$[\mathrm{M}-\mathrm{H}]^{-}$} & 244.1327 & 244.1311 & 6.47 & $\begin{array}{l}207.1044 \\
71.0506\end{array}$ & $\begin{array}{l}\text { (E)-4-hydroxy-dodec-2- } \\
\text { enedioic acid [1] }\end{array}$ \\
\hline 31 & 9.693 & $\mathrm{C}_{21} \mathrm{H}_{32} \mathrm{O}_{8}$ & {$[\mathrm{M}+\mathrm{COOH}]^{-}$} & 412.2116 & 412.2097 & 4.67 & $\begin{array}{l}327.1466 \\
61.9893\end{array}$ & $\begin{array}{l}\text { 7a(H)-eudesmane-4,11(12)- } \\
\text { diene-3-one-2 } \beta \text {-hydroxy-13- } \beta \text { - } \\
\text { D-glucopyranoside [13] }\end{array}$ \\
\hline 32 & 10.16 & $\mathrm{C}_{7} \mathrm{H}_{30} \mathrm{O}_{3}$ & {$[\mathrm{M}+\mathrm{COOH}]^{-}$} & 282.2207 & 282.2195 & 4.37 & & $\begin{array}{l}(-)-\left(1 S^{\star}, 2 S^{*}, 3 R^{\star}\right)-3- \\
\text { ethoxycupar-5-ene-1,2-diol [1] }\end{array}$ \\
\hline 33 & 10.191 & $\mathrm{C}_{15} \mathrm{H}_{10} \mathrm{O}_{7}$ & {$[\mathrm{M}-\mathrm{H}]^{-}$} & 302.0441 & 302.0427 & 4.93 & 151.0046 & quercetin [20] \\
\hline 34 & 10.308 & $\mathrm{C}_{30} \mathrm{H}_{26} \mathrm{O}_{13}$ & {$[\mathrm{M}-\mathrm{H}]^{-}$} & 594.1395 & 594.1373 & 3.66 & $\begin{array}{l}447.0934 \\
285.0418 \\
145.0305\end{array}$ & tiliroside [17] \\
\hline 35 & 10.542 & $\mathrm{C}_{30} \mathrm{H}_{26} \mathrm{O}_{13}$ & {$[\mathrm{M}-\mathrm{H}]^{-}$} & 594.1396 & 594.1373 & 3.84 & $\begin{array}{l}\text { 447.0630, } \\
285.0417 \\
145.0304\end{array}$ & $\begin{array}{l}\text { kaempferol-3-O-( } 6 \text { "-O-cis-p- } \\
\text { coumaroyl) - } \beta \text {-D- } \\
\text { glucopyranoside }[12,19]\end{array}$ \\
\hline 36 & 11.216 & $\mathrm{C}_{15} \mathrm{H}_{10} \mathrm{O}_{6}$ & {$[\mathrm{M}-\mathrm{H}]^{-}$} & 286.0493 & 286.0477 & 5.49 & 65.0044 & Kaempferol [21] \\
\hline 37 & 11.333 & $\mathrm{C}_{10} \mathrm{H}_{18} \mathrm{O}_{2}$ & {$[\mathrm{M}+\mathrm{COOH}]^{-}$} & 170.1319 & 170.1307 & 6.98 & $\begin{array}{l}\text { 153.1285, } \\
68.9956\end{array}$ & $\begin{array}{l}\text { 2,6-dimethyl-2E,7-octadiene- } \\
\text { 1,6-diol [17] }\end{array}$ \\
\hline 38 & 11.45 & $\mathrm{C}_{15} \mathrm{H}_{10} \mathrm{O}_{5}$ & {$\left[\mathrm{M}+\mathrm{COOCH}_{3}\right]^{-}$} & 270.0545 & 270.0528 & 6.24 & & apigenin [22] \\
\hline 39 & 12.036 & $\mathrm{C}_{13} \mathrm{H}_{16} \mathrm{O}$ & {$\left[\mathrm{M}+\mathrm{COOCH}_{3}\right]^{-}$} & 188.1192 & 188.1201 & -5.09 & $\begin{array}{l}\text { 185.9999, } \\
75.0097\end{array}$ & $\begin{array}{l}\text { 2-(1-oxopentyl)-benzoic acid } \\
\text { methyl ester [17] }\end{array}$ \\
\hline 40 & 12.241 & $\mathrm{C}_{15} \mathrm{H}_{30} \mathrm{O}_{2}$ & {$[\mathrm{M}+\mathrm{COOH}]^{-}$} & 242.2261 & 242.2246 & 6.09 & & methyl tetradecanoate [17] \\
\hline 41 & 12.563 & $\mathrm{C}_{16} \mathrm{H}_{12} \mathrm{O}_{5}$ & {$[\mathrm{M}-\mathrm{H}]^{-}$} & 284.0698 & 284.0685 & 4.58 & $\begin{array}{l}268.0395 \\
117.0356\end{array}$ & wogonin [21] \\
\hline
\end{tabular}




\begin{tabular}{|c|c|c|c|c|c|c|c|c|}
\hline & $t_{R}(\min )$ & MF & Product ion & Mass & Mass(Tgt) & Diff(ppm) & $\begin{array}{l}(-) \text {-ESI- } \\
\text { MS/MS } \\
\text { Fragment } \\
\text { lons } \\
(\mathrm{m} / \mathrm{z})\end{array}$ & Identification [Reference] \\
\hline 42 & 13.244 & $\mathrm{C}_{16} \mathrm{H}_{12} \mathrm{O}_{5}$ & {$[\mathrm{M}-\mathrm{H}]^{-}$} & 284.0700 & 284.0685 & 5.51 & $\begin{array}{l}268.0395 \\
117.0356\end{array}$ & $\begin{array}{l}\text { 4',5-dihydroxy-7- } \\
\text { methoxyflavone [19] }\end{array}$ \\
\hline 43 & 13.444 & $\mathrm{C}_{15} \mathrm{H}_{10} \mathrm{O}_{4}$ & {$[\mathrm{M}+\mathrm{COOH}]^{-}$} & 254.0593 & 254.0579 & 5.61 & $\begin{array}{l}284.0342, \\
133.0305\end{array}$ & daidzein [19] \\
\hline 44 & 13.978 & $\mathrm{C}_{21} \mathrm{H}_{32} \mathrm{O}_{6}$ & {$[\mathrm{M}+\mathrm{COOH}]^{-}$} & 380.2201 & 380.2199 & 0.50 & $\begin{array}{l}263.1668 \\
61.9892\end{array}$ & $\begin{array}{l}(-)- \\
(5 S, 7 R, 8 R, 9 R, 10 S, 13 S, 15 R)-7- \\
\text { hydroxy-15-methoxy- } \\
\text { 9,13;15,16-diepoxylabdan- } \\
\text { 6,16-dione [1] }\end{array}$ \\
\hline 45 & 15.502 & $\mathrm{C}_{15} \mathrm{H}_{24} \mathrm{O}_{4}$ & {$[\mathrm{M}-\mathrm{H}]^{-}$} & 268.1687 & 268.1675 & 4.72 & & $\begin{array}{l}\text { 7a(H),10a-eudesm-4-en- } \\
\text { 3one-2 } \beta, 11,12 \text {-triol [15] }\end{array}$ \\
\hline 46 & 18.29 & $\mathrm{C}_{20} \mathrm{H}_{28} \mathrm{O}_{4}$ & {$\left[\mathrm{M}+\mathrm{COOCH}_{3}\right]^{-}$} & 332.1981 & 332.1988 & -2.01 & & $\begin{array}{l}\text { (-)-3a-acetoxy-6 } \beta \text {-hydroxy- } \\
\text { 15,16-dinorlabd-8(9)-ene-13- } \\
\text { yne-7-one [19] }\end{array}$ \\
\hline 47 & 19.769 & $\mathrm{C}_{30} \mathrm{H}_{48} \mathrm{O}_{4}$ & {$[\mathrm{M}-\mathrm{H}]^{-}$} & 472.3571 & 472.3553 & 3.80 & $\begin{array}{l}\text { 409.3488, } \\
171.1035 \\
61.9893\end{array}$ & messagenic acid [23] \\
\hline 48 & 19.881 & $\mathrm{C}_{29} \mathrm{H}_{46} \mathrm{O}_{2}$ & {$[\mathrm{M}+\mathrm{COOH}]^{-}$} & 426.3516 & 426.3498 & 4.25 & $\begin{array}{l}\text { 409.3488, } \\
\text { 171.1035, } \\
61.9893\end{array}$ & $\begin{array}{l}\text { (24S)-stigmast-4,28-diene- } \\
\text { 24-ol-3-one [23] }\end{array}$ \\
\hline 49 & 20.276 & $\mathrm{C}_{20} \mathrm{H}_{40} \mathrm{O}$ & {$\left[\mathrm{M}+\mathrm{COOCH}_{3}\right]^{-}$} & 296.3097 & 296.3079 & 6.14 & & phytol [23] \\
\hline
\end{tabular}


Table 3

\begin{tabular}{|c|c|c|c|}
\hline \multicolumn{2}{|c|}{\begin{tabular}{|l|l|} 
Peak & Chemical type \\
No. &
\end{tabular}} & \begin{tabular}{l|l} 
Compounds \\
\end{tabular} & \multirow{2}{*}{$\begin{array}{l}\text { MF } \\
\mathrm{C}_{14} \mathrm{H}_{21} \mathrm{~N}_{3} \mathrm{O}_{5}\end{array}$} \\
\hline C1 & Alkaloid & leonurine & \\
\hline $\mathrm{C} 2$ & Alkaloid & tryptophan & $\mathrm{C}_{11} \mathrm{H}_{12} \mathrm{~N}_{2} \mathrm{O}_{2}$ \\
\hline C3 & Flavonoid & 4',5-dihydroxy-7-methoxyflavone & $\mathrm{C}_{16} \mathrm{H}_{12} \mathrm{O}_{5}$ \\
\hline $\mathrm{C} 4$ & Flavonoid & rutin & $\mathrm{C}_{27} \mathrm{H}_{30} \mathrm{O}_{16}$ \\
\hline C5 & Flavonoid & quercetin-3-0-robinoside & $\mathrm{C}_{27} \mathrm{H}_{30} \mathrm{O}_{16}$ \\
\hline C6 & Flavonoid & tiliroside & $\mathrm{C}_{30} \mathrm{H}_{26} \mathrm{O}_{13}$ \\
\hline C7 & Flavonoid & kaempferol-3-0- $\beta$-D-glucopyranoside & $\mathrm{C}_{21} \mathrm{H}_{20} \mathrm{O}_{11}$ \\
\hline C8 & Flavonoid & 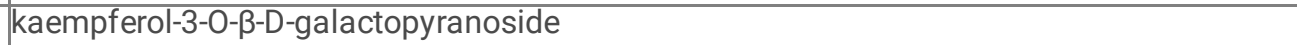 & $\mathrm{C}_{21} \mathrm{H}_{20} \mathrm{O}_{11}$ \\
\hline C9 & Flavonoid & kaempferol-3-neohesperidoside & $\mathrm{C}_{27} \mathrm{H}_{30} \mathrm{O}_{15}$ \\
\hline C10 & Flavonoid & kaempferol-3-0-rutinoside & $\mathrm{C}_{27} \mathrm{H}_{30} \mathrm{O}_{15}$ \\
\hline C11 & Flavonoid & hyperoside & $\mathrm{C}_{21} \mathrm{H}_{20} \mathrm{O}_{12}$ \\
\hline C12 & Flavonoid & quercetin-3-0- $\beta$-D-glucopyranoside & $\mathrm{C}_{21} \mathrm{H}_{20} \mathrm{O}_{12}$ \\
\hline C13 & Flavonoid & daidzein & $\mathrm{C}_{15} \mathrm{H}_{10} \mathrm{O}_{4}$ \\
\hline C14 & Flavonoid & 2"'-syringylrutin & $\mathrm{C}_{36} \mathrm{H}_{38} \mathrm{O}_{20}$ \\
\hline C15 & Flavonoid & apigenin & $\mathrm{C}_{15} \mathrm{H}_{10} \mathrm{O}_{5}$ \\
\hline C16 & Flavonoid & quercetin & $\mathrm{C}_{15} \mathrm{H}_{10} \mathrm{O}_{7}$ \\
\hline C17 & Flavonoid & kaempferol & $\mathrm{C}_{15} \mathrm{H}_{10} \mathrm{O}_{6}$ \\
\hline C18 & Terpenoids & staphylionoside E & $\mathrm{C}_{19} \mathrm{H}_{32} \mathrm{O}_{8}$ \\
\hline C19 & Terpenoids & citroside A & $\mathrm{C}_{19} \mathrm{H}_{30} \mathrm{O}_{8}$ \\
\hline $\mathrm{C} 20$ & Terpenoids & 7a(H)-eudesmane-4,11(12)-diene-3-one-2 $\beta$-hydroxy-13- $\beta$-D-glucopyranoside & $\mathrm{C}_{21} \mathrm{H}_{32} \mathrm{O}_{8}$ \\
\hline C21 & Terpenoids & (-)-(5S,7R,8R,9R,10S,13S,15R)-7-hydroxy-15-methoxy-9,13;15,16-diepoxylabdan-6,16-dione & $\mathrm{C}_{21} \mathrm{H}_{32} \mathrm{O}_{6}$ \\
\hline $\mathrm{C} 22$ & Aromatic acids & (E)-4-hydroxy-dodec-2-enedioic acid & $\mathrm{C}_{12} \mathrm{H}_{20} \mathrm{O}_{5}$ \\
\hline $\mathrm{C} 23$ & Other types & phenylalanine & $\mathrm{C}_{9} \mathrm{H}_{11} \mathrm{NO}_{2}$ \\
\hline C24 & $\begin{array}{l}\text { Phenylethanoid } \\
\text { glycosides }\end{array}$ & lavandulifolioside & $\mathrm{C}_{34} \mathrm{H}_{44} \mathrm{O}_{19}$ \\
\hline $\mathrm{C} 25$ & Other types & $(-)-\left(1 S^{\star}, 2 S^{\star}, 3 R^{\star}\right)-3-e t h o x y c u p a r-5-e n e-1,2-$ diol & $\mathrm{C}_{17} \mathrm{H}_{30} \mathrm{O}_{3}$ \\
\hline $\mathrm{C} 26$ & Other types & messagenic acid & $\mathrm{C}_{30} \mathrm{H}_{48} \mathrm{O}_{4}$ \\
\hline $\mathrm{C} 27$ & Other types & phytol & $\mathrm{C}_{20} \mathrm{H}_{40} \mathrm{O}$ \\
\hline $\mathrm{C} 28$ & Aromatic acids & syringic acid & $\mathrm{C}_{9} \mathrm{H}_{10} \mathrm{O}_{5}$ \\
\hline $\mathrm{C} 29$ & Other types & 2,6-dimethoxy-4-hydroxyphenol-1-0- $\beta$-D-glucopyranoside & $\mathrm{C}_{14} \mathrm{H}_{20} \mathrm{O}_{9}$ \\
\hline C30 & Aromatic acids & salicylic acid & $\mathrm{C}_{7} \mathrm{H}_{6} \mathrm{O}_{3}$ \\
\hline C31 & Other types & ethyl 4-hydroxybenzoate & $\mathrm{C}_{9} \mathrm{H}_{10} \mathrm{O}_{3}$ \\
\hline C32 & Flavonoid & wogonin & $\mathrm{C}_{16} \mathrm{H}_{12} \mathrm{O}_{5}$ \\
\hline C33 & Terpenoids & (-)-3a-acetoxy-6ß-hydroxy-15,16-dinorlabd-8(9)-ene-13-yne-7-one & $\mathrm{C}_{20} \mathrm{H}_{28} \mathrm{O}_{4}$ \\
\hline
\end{tabular}

Common fingerprint peaks of the fingerprint of Leonuri Herba in different origins

\section{Table 4}

Principal component scores, comprehensive evaluation, and fine sorting of Leonuri Herba

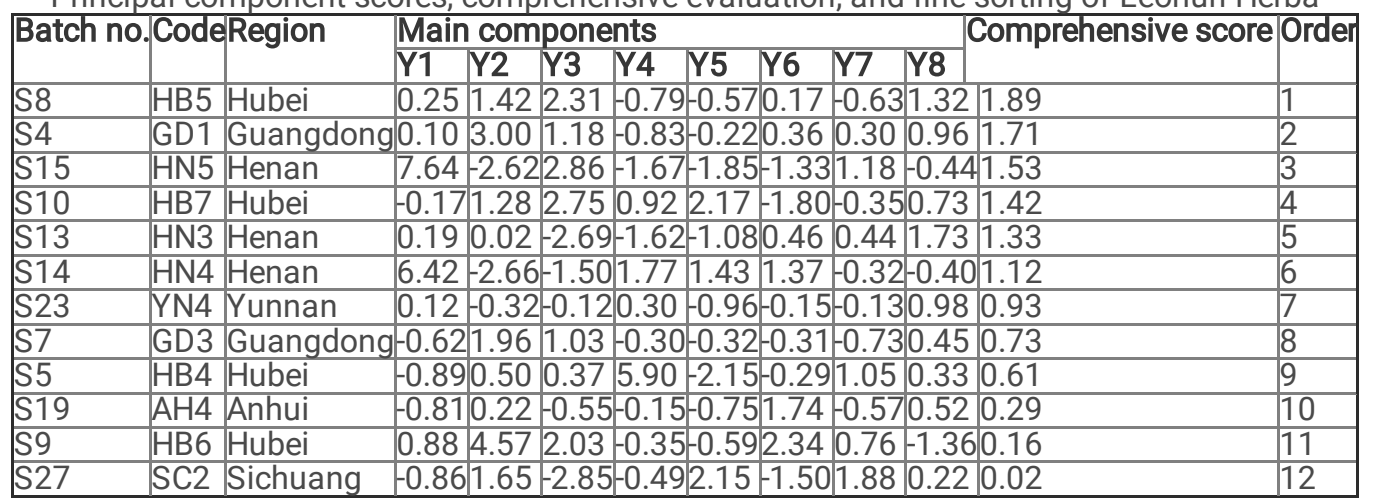


Table 5

The Contents $(\mu \mathrm{g} / \mathrm{g})$ of the eight marker compounds in 30 samples of Leonuri Herba

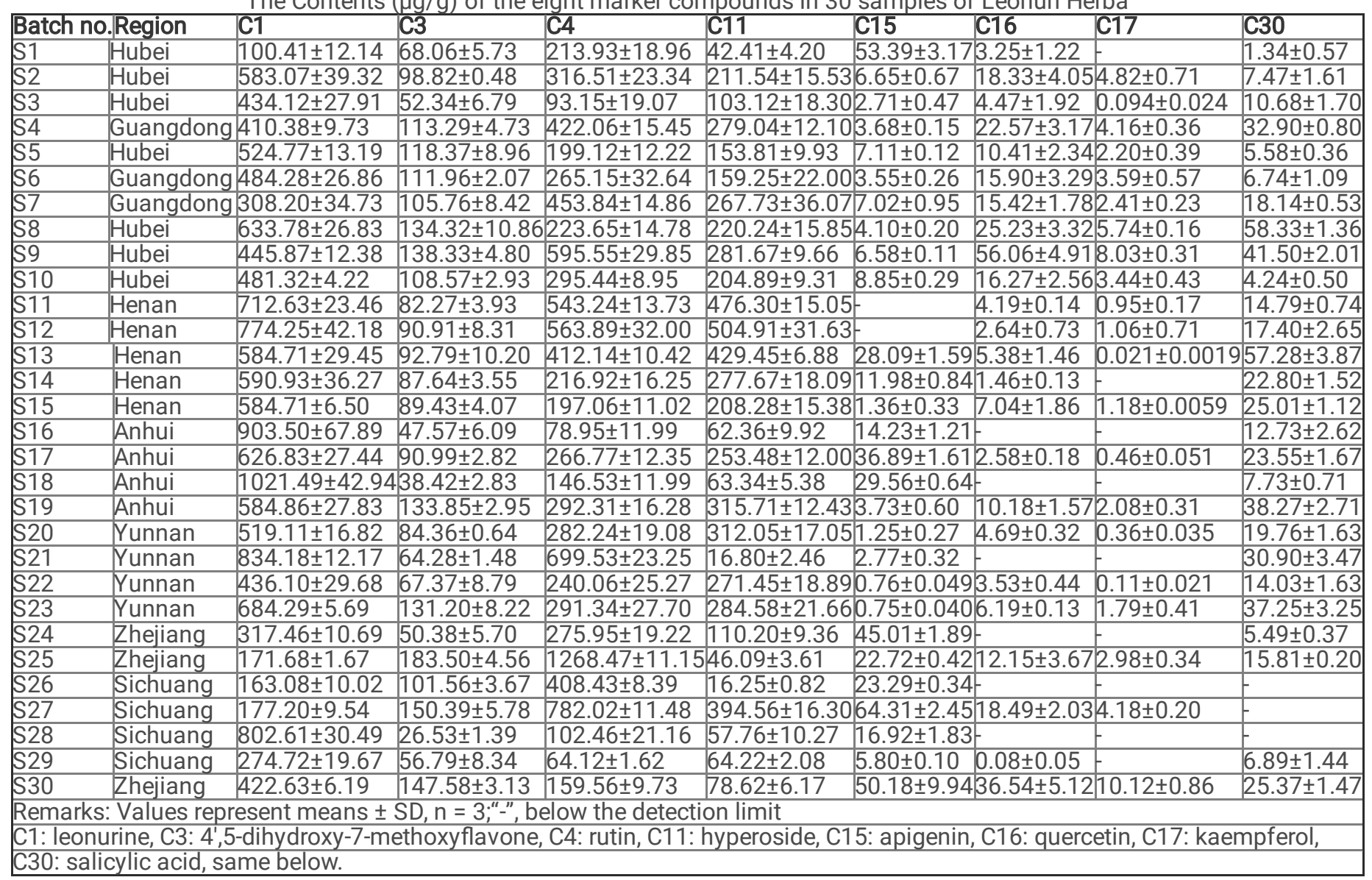

Figures
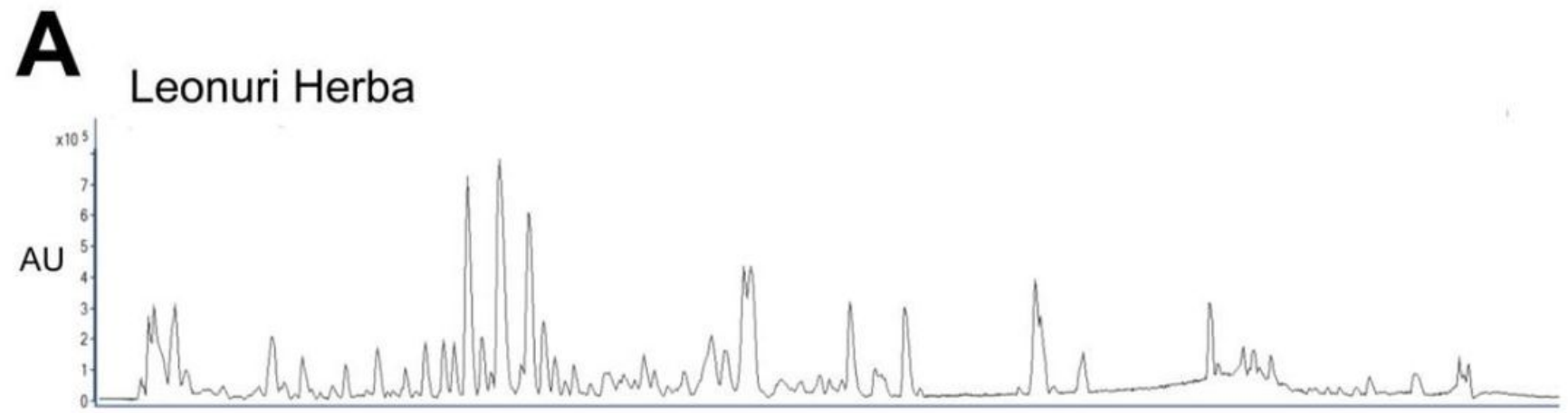

B

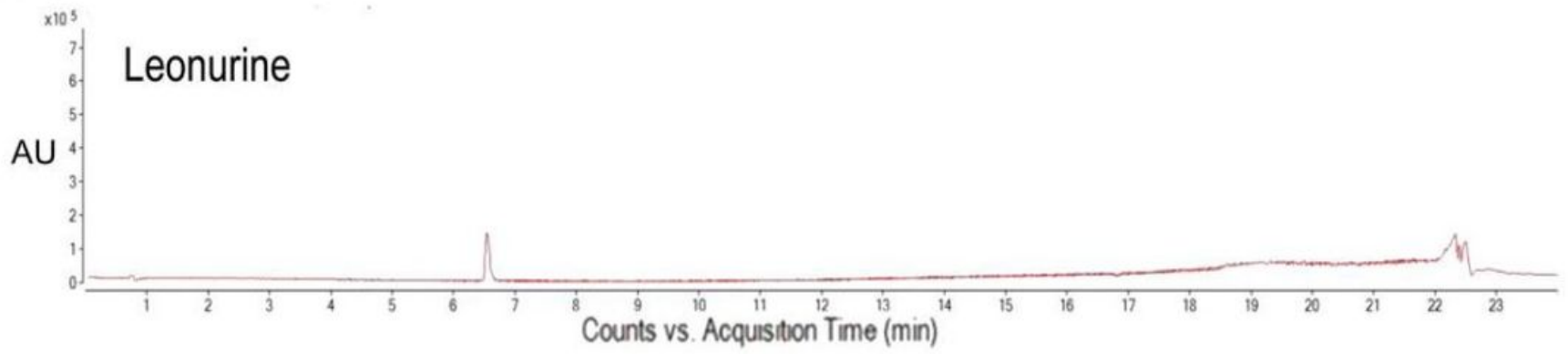

Figure 1

Page 14/17 
The BPC of Leonuri Herba (A) and Leonurine(B) in negative mode

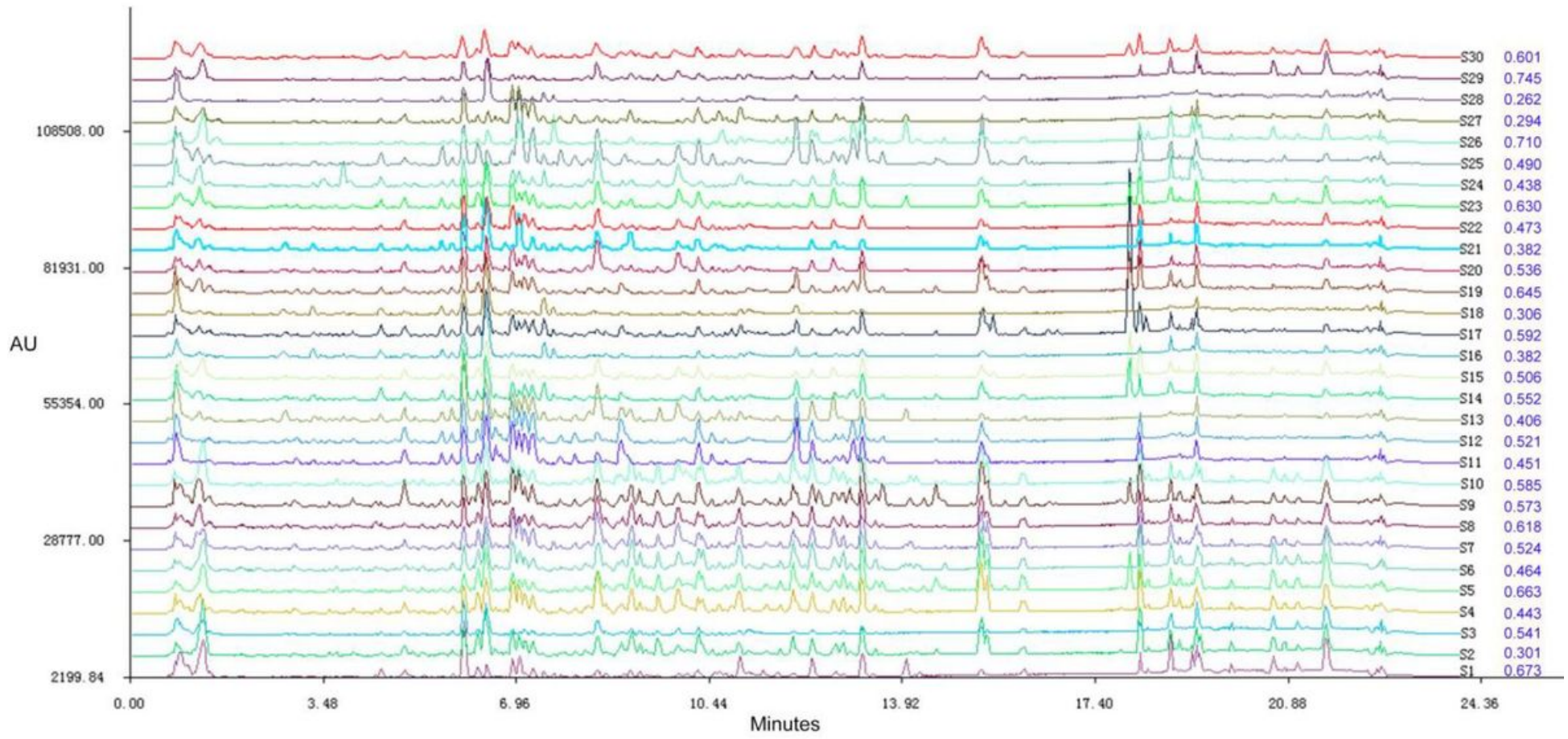

Figure 2

Overlay chromatograms of the 30 Leonuri Herba samples and the similarity of each chromatogram to their simulated mean chromatogram in blue

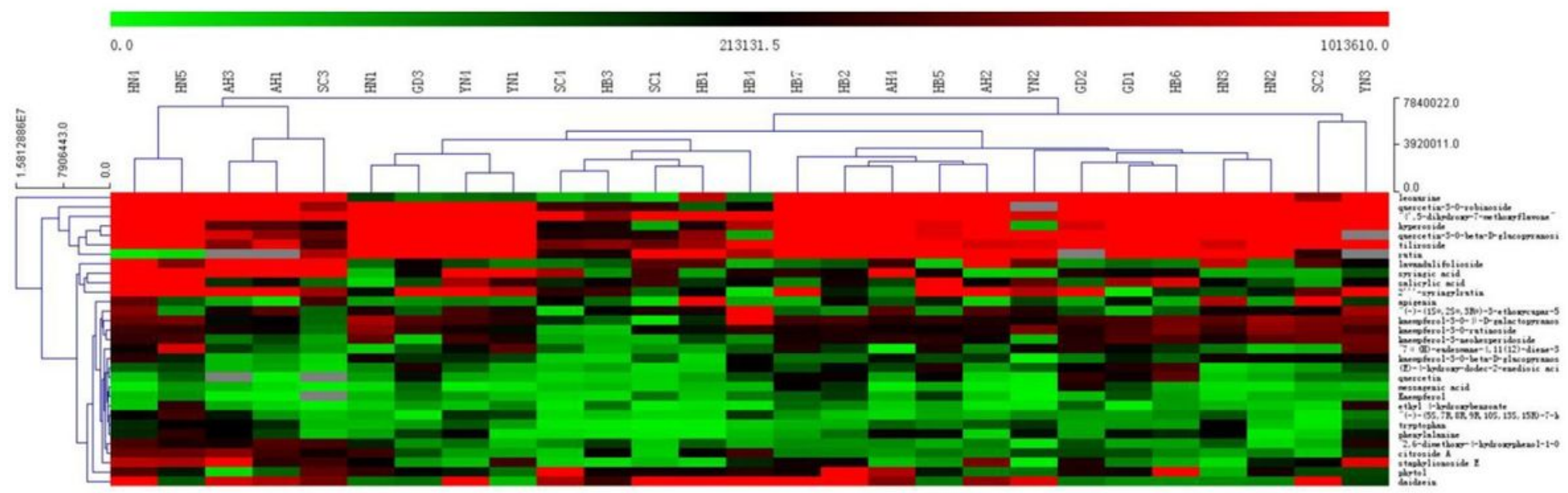

\section{Figure 3}

Hierarchical clustering analysis of Leonuri Herba from different origins and batches 

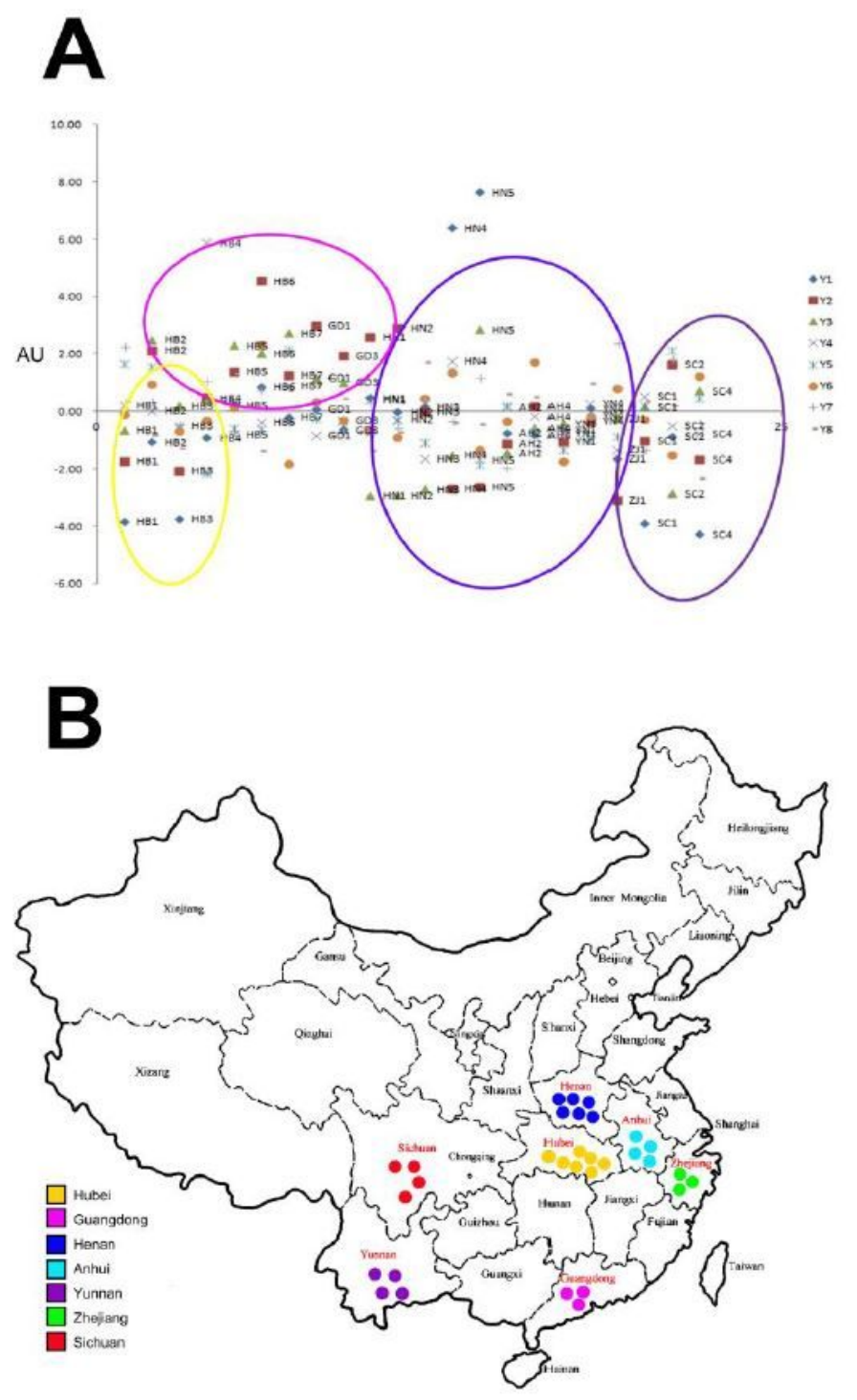

Figure 4

$\mathrm{PCA} /$ score plot $(\mathrm{A})$ based on the chemical profiling of 30 samples from different origins and the regional distribution of the corresponding 30 samples (B). 


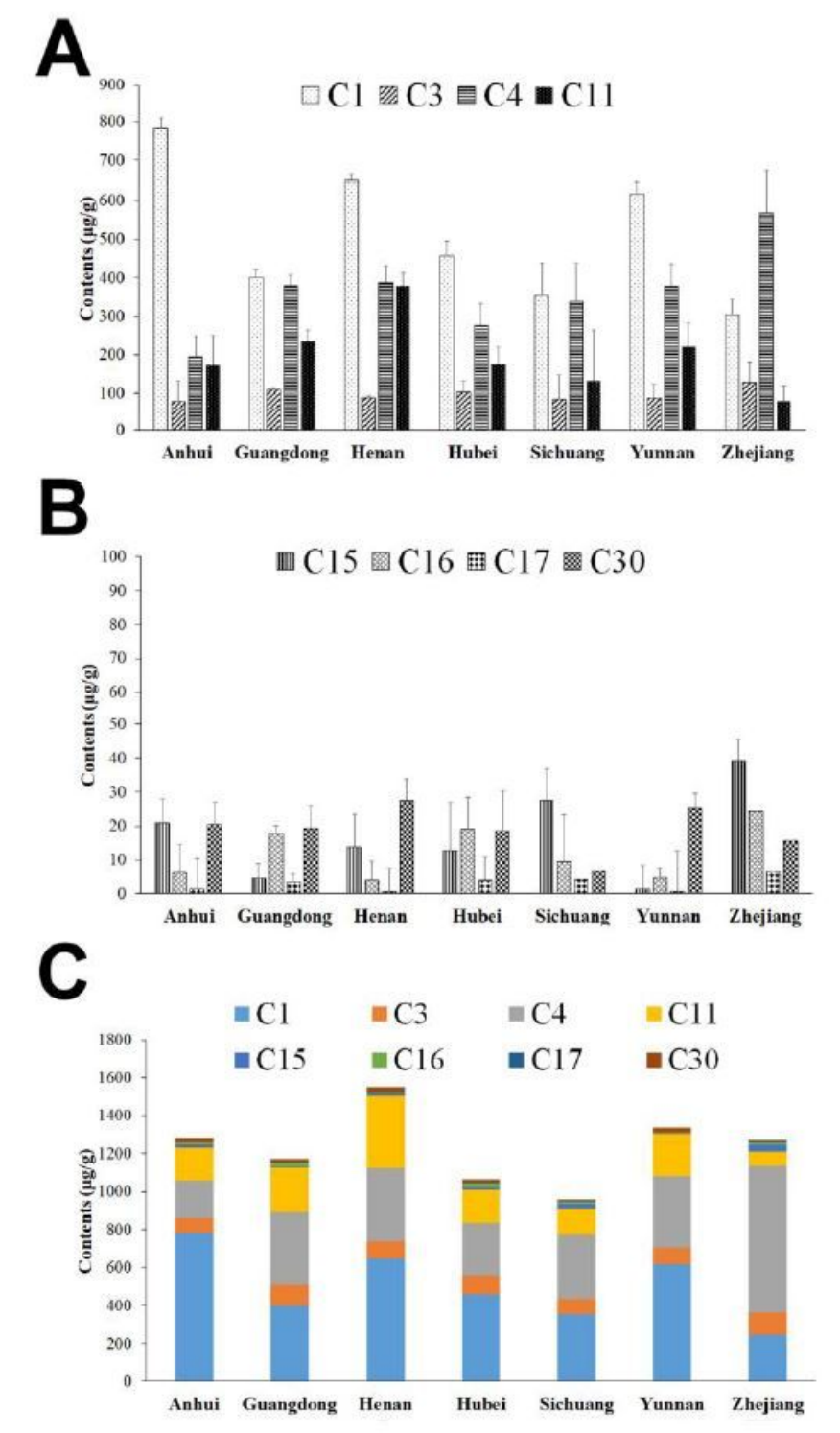

Figure 5

The contents of 8 components in the 30 samples from different regions (A): the content of Leonurine(C1), 4',5-dihydroxy-7methoxyflavone(C3), rutin (C4) and hyperoside(C11). (B): the content of apigenin(C15), quercetin(C16), kaempferol (C17) and salicylic acid (C30). (C): the content of combination of 8 components in 30 samples.

\section{Supplementary Files}

This is a list of supplementary files associated with this preprint. Click to download.

- Additionfile1.jpg

- Additionalfile23Table.docx 